\title{
ANALISIS KEBUTUHAN KECEPATAN BANDWIDTH GAME ONLINE (Free fire, Mobile Legends, PUBG mobile)
}

\author{
Ahmad Tantoni1, Mohammad Taufan Asri Zaen², Khairul Imtihan³ \\ 1,Program Studi Teknik Informatika STMIK Lombok, \\ 2,3Program Studi Sistem Informasi, STMIK Lombok
}

Jln. Basuki Rahmat No.105 Praya Lombok Tengah 83511

1ahmad.tantoni@students.amikom.ac.id, ${ }^{2}$ opanzain@gmail.com, ${ }^{3}$ khairulimtihan31@gmail.com

\begin{abstract}
Online Game users continue to grow from year to year and therefore internet service providers (ISPS) must provide stable and fast internet quality. The Bandwidth requirements of online Games must be supported by internet networks that support the speed and stability of the internet connection. When using online Games sometimes the connection is bad, so it makes a condition called lagging. Then make the online Game avatars do not move or the traffic is stuck. This makes online Game players lose to enemies because, when the online Game avatar is not moving it will be easy for the enemy to shoot dead. Based on this, an analysis of the research needs of online Game Bandwidth speed needs to be done so, that internet service providers (ISPS) can divide how much speed or Bandwidth to the Game needs so, that online Game users feel comfortable, safe without feeling any slow or lagging conditions. This study tested by 3 Games, such as Free fire, Mobile Legends, and Pubg mobile. Each Game uses graphics and image quality which is being tested for 10 minutes. The results of this study shows that all of the three Games requires a stable internet connection for Uploading and Downloading.
\end{abstract}

Keywords: Game online, Bandwidth, free fire, Mobile Legends, pubg mobile

\begin{abstract}
Abstrak
Pengguna Game online terus bertambah dari tahun ketahun maka dari itu penyedia layanan internet (ISP) harus menyediakan kualitas internet yang stabil dan cepat. Kebutuhan Bandwidth Game online harus didukung dengan jaringan internet yang mendukung dalam hal kecepatan dan kesetabilan koneksi internet. Pada saat menggunakan Game online terkadang koneksi buruk sehingga menjadikan kondisi yang dinamakan nge-lag. Kemudian membuat avatar Game online tidak bergerak atau trafik tersendat. Hal ini membuat pemain Game online akan kalah melawan musuh karna saat avatar Game online tersebut tidak bergerak akan mudah untuk musuh melakukan tembak mati. Berdasar hal tersebut, maka dilakukan penelitian analisis kebutuhan kecepatan Bandwidth Game online agar penyedia layanan internet (ISP) bisa mengalokasikan berapa kecepatan atau Bandwidth pada kebutuhan Game supaya pengguna Game online merasa nyaman, aman tanpa merasa ada kondisi lambat atau nge-lag. Penelitian ini mengujikan 3 Game yaitu Free fire, Mobile Legends dan Pubg mobile dan masing-masing Game menggunakan grafik atau kualitas gambar yang sedang dengan pengujian selama 10 menit. Hasil dari penelitian menunjukkan ketiga Game membutuhkan koneksi internet yang stabil untuk proses Upload dan Download.
\end{abstract}

Kata kunci : Game online, Bandwidth, free fire, Mobile Legends, pubg mobile 


\section{Pendahuluan}

Perkembangan pemakaian internet semakin hari meningkat. Data yang dilansir oleh Asosiasi Penyelenggara Jasa Internet Indonesia (APJII) pada bulan oktober 2016 terdapat 132,7 juta masyarakat Indonesia menggunakan internet. Dari 132,7 juta orang Indonesia hampir $80 \%$ berusia antara 15-29 tahun, dan jika dilihat dari perangkat dipakai, hampir 47,6\% menggunakan perangkat mobile/smartphone. Dilihat dari data ini sangat mungkin Game online ada di gadget/smartphone tersebut.

Game online merupakan permainan di dunia maya yang didalamnya pertandingan manusia dengan manusia menggunakan device yang terhubung ke jaringan internet dan pertandingan bisa dalam antar lokal, antar negara bahkan skala dunia. Sedangkan Bandwidth [1] merupakan luas atau lebar cakupan frekuensi yang digunakan oleh sinyal dalam medium transmisi. Bandwidth dapat diartikan sebagai perbedaan antara komponen sinyal frekuensi tinggi dan sinyal frekuensi rendah. Frekuensi sinyal diukur dalam satuan Hertz.

Sampai saat ini pengguna Game online terus bertambah dari tahun ketahun maka dari itu penyedia layanan internet (ISP) harus menyediakan kualitas internet yang stabil dan cepat. Kebutuhan Bandwidth Game online harus didukung dengan jaringan internet yang mendukung dalam hal kecepatan dan kesetabilan koneksi internet

Pada saat menggunakan Game online terkadang ada kalanya koneksi buruk sehingga menjadikan kondisi yang dinamakan nge-lag. Kemudian membuat avatar Game online tidak bergerak atau trafik tersendat, hal ini membuat pemain Game online akan kalah melawan musuh karna saat avatar Game online tersebut tidak bergerak akan mudah untuk musuh melakukan tembak mati.

Dari latar belakang itu, maka dilakukan penelitian analisis kebutuhan kecepatan Bandwidth Game online supaya penyedia layanan internet (ISP) bisa mengalokasikan berapa kecepatan atau Bandwidth pada kebutuhan Game agar pengguna Game online merasa nyaman, aman tanpa merasa ada kondisi lambat atau nge-lag. Penelitian ini mengujikan 3 Game yaitu Free fire, Mobile Legends dan Pubg mobile dan masing-masing Game menggunakan grafik atau kualitas gambar yang sedang dengan pengujian selama 10 menit.

\section{Tinjauan Pustaka dan Teori \\ A. Tinjauan Pustaka}

Penelitian Ananta, dkk tentang routing pada warnet pada mitha.net menggunakan 2 line telkom. Permasalahan yang terjadi disaat beberapa client warnet Download atau streaming maka client Game terjadi putus-putus saat bermain Game atau sering disebut dengan nge-lag. Ini tentu mengganggu kenyamanan pelanggan. Sehingga penggunaan dua line ISP dari Telkom Speedy menjadi pilihan. Untuk memenuhi kebutuhan dalam hal kenyamanan koneksi internet, dibutuhkan pengaturan Bandwidth yang seimbang antara Game, streaming, Download dan browsing sehingga harus ada pengaturan khusus dalam routing. Perbedaannya dengan penelitian ini membandingkan masing-masing kebutuhan Bandwidth dari 3 Game online yang berbeda [2].

Setiawan, dkk dalam penelitiannya terkait dengan implementasi dan analisis Mobile Cloud Gaming online menggunakan open-source cloud gaming server gaming anywhere pada perangkat android. Penelitian ini hanya implementasi dan analisis Mobile Cloud Gaming online menggunakan open-source sedangkan perbedaannya dengan penelitian ini membandingkan masing-masing kebutuhan Bandwidth dari 3 Game online yang berbeda [3].

Penelitian Mutia, dkk tentang analisis performasi jaringan untuk layanan interaktif. Penelitian ini, menganalisa karakteristik dari Game-online itu sendiri. Seperti, analisis pengaruh dari QoS dengan port yang digunakan serta keterhubungannya dengan Bandwidth management. Pengaruh port yang digunakan oleh masing-masing Game-online. Penelitian ini lebih berfokus pada Game DOTA dengan pengaturan protokol TCP dan UTP sedangkan penelitian yang akan dilakukan membandingkan masing-masing kebutuhan Bandwidth dari 3 Game online yang berbeda [4].

Penelitian Togohodoh dengan tema manajemen Bandwidth dengan metode peer connection queue (PCQ) menggunakan queue tree. Penelitian ini lebih berfokus pada manajemen Bandwidth untuk jaringan secara umum pada setingan router sedangkan tidak seesifikik ke pengaturan Bandwidth Game online. Peneltian yang akan dilakukan membandingkan masing-masing kebutuhan Bandwidth dari 3 Game online yang berbeda [5]. 


\section{B. Bandwidth}

Menurut Norton dan Kearns [6], Bandwidth adalah lebar komunikasi diantara saluran yang diukur dalam Hz. Sedangkan menurut Mulyanta [1], Bandwidth merupakan luas atau lebar cakupan frekuensi yang digunakan oleh sinyal dalam medium transmisi. Bandwidth dapat diartikan sebagai perbedaan antara komponen sinyal frekuensi tinggi dan sinyal frekuensi rendah. Frekuensi sinyal diukur dalam satuan Hertz

Menurut E. Setio Dewo [7] Bandwidth adalah suatu ukuran dari banyaknya informasi yang dapat mengalir dari suatu tempat ke tempat lain dalam suatu waktu tertentu. Bandwidth dapat dipakaikan untuk mengukur baik aliran data analog mau pun aliran data digital. Sekarang telah menjadi umum jika kata Bandwidth lebih banyak dipakaikan untuk mengukur aliran data digital. Satuan yang dipakai untuk Bandwidth adalah bits per second atau sering disingkat sebagai bps. Seperti kita tahu bahwa bit atau binary digit adalah basis angka yang terdiri dari angka 0 dan 1 . Satuan ini menggambarkan seberapa banyak bit (angka 0 dan 1) yang dapat mengalir dari satu tempat ke tempat yang lain dalam setiap detiknya melalui suatu media.

Bandwidth adalah konsep pengukuran yang sangat penting dalam jaringan, tetapi konsep ini memiliki kekurangan atau batasan, tidak peduli bagaimana cara Anda mengirimkan informasi mau pun media apa yang dipakai dalam penghantaran informasi. Hal ini karena adanya hukum fisika mau pun batasan teknologi. Ini akan menyebabkan batasan terhadap panjang media yang dipakai, kecepatan maksimal yang dapat dipakai, mau pun perlakuan khusus terhadap media yang dipakai.

\section{Throughput}

Konsep Bandwidth tidak cukup untuk menjelaskan kecepatan jaringan dan apa yang terjadi di jaringan. Untuk itulah konsep Throughput muncul. Throughput [7] adalah Bandwidth aktual yang terukur pada suatu ukuran waktu tertentu dalam suatu hari menggunakan rute internet yang spesifik ketika sedang menDownload suatu file. Bagaimana cara mengukur Bandwidth? Dan bagaimana hubungannya dengan throughput? Seperti telah diulas di atas, Bandwidth adalah jumlah bit yang dapat dikirimkan dalam satu detik. Sedangkan throughput walau pun memiliki satuan dan rumus yang sama dengan Bandwidth, tetapi throughput lebih pada menggambarkan Bandwidth yang sebenarnya (aktual) pada suatu waktu tertentu dan pada kondisi dan jaringan internet tertentu yang digunakan untuk menDownload suatu file dengan ukuran tertentu.

\section{Mikrotik}

Mikrotik adalah sebuah merek dari perangkat jaringan, pada awalnya Mikrotik hanyalah sebuah perangkat lunak atau software yang diinstall dalam komputer yang digunakan untuk mengontrol jaringan, tetapi dalam perkembangannya saat ini menjadi sebuah device atau perangkat jaringan yang anda dan harga yang terjangkau, serta banyak digunakan pada level perusahaan jasa internet (ISP). [8]

\section{E. Game online}

Dikutip dari [9], perkembangan Game online sendiri tidak lepas juga dari perkembangan teknologi komputer dan jaringan komputer itu sendiri. Meledaknya Game online sendiri merupakan cerminan dari pesatnya jaringan komputer yang dahulunya berskala kecil (small local network) sampai menjadi internet dan terus berkembang sampai sekarang. Pada saat muncul pertama kalinya tahun 1969, komputer hanya bisa dipakai untuk 2 orang saja untuk bermain Game. Lalu munculah komputer dengan kemampuan timesharing sehingga pemain yang bisa memainkan Game tersebut bisa lebih banyak dan tidak harus berada disuatu ruangan yang sama (Multiplayer Games).

Game adalah aktivitas yang dilakukan untuk fun atau menyenangkan yang memiliki aturan sehingga ada yang menang dan ada yang kalah. Selain itu, Game membawa arti sebuah kontes, fisik atau mental, menurut aturan tertentu, untuk hiburan, rekreasi, atau untuk menang taruhan.

Menurut Eddy Liem, Direktur Indonesia Gamer, sebuah pencinta Games di Indonesia, Game online adalah sebuah Game atau permainan yang dimainkan secara online via internet, bisa menggunakan PC (personal computer) atau konsul Game biasa seperti PS2 ,X-Box dan sejenisnya.

Berikut beberapa genre Game online yang dikenalkan pada masyarakat [10] :

- First Person Shooter (FPS), sesuai judulnya Game ini mengambil pandangan orang pertama pada Gamenya sehingga seolaholah kita sendiri yang berada dalam Game tersebut, kebanyakan Game ini mengambil setting peperangan dengan senjata-senjata 
militer (di Indonesia, Game jenis ini sering disebut Game tembak-tembakan). Contoh Game genre ini antara lain Duke Nukem 3D, Quake, Blood, Unreal, Unreal Tournament, Half-Life, Counter-Strike, Halo, Perfect Dark, TimeSplitters, Call of Duty, System Shock, dan GoldenEye 007.

- Real-Time Strategy, merupakan Game yang permainannya menekankan kepada kehebatan strategi pemainnya, biasanya pemain memainkan tidak hanya 1 karakter saja akan tetapi banyak karakter. Contoh Age of Empires, Rise of Nations, Stronghold, Warcraft.

- Cross-Platform Online, merupakan Game yang dapat dimainkan secara online dengan hardware yang berbeda misalnya saja Need For Speed Undercover dapat dimainkan secara online dari PC maupun Xbox 360 (Xbox 360 merupakan hardware/console Game yang memiliki konektivitas ke internet sehingga dapat bermain secara online).

- Browser Games, merupakan Game yang dimainkan pada browser seperti Firefox, Opera, IE. Syarat dimana sebuah browser dapat memainkan Game ini adalah browser sudah mendukung javascript, php, maupun flash.

Massive Multiplayer Online Games Role Playing Game (MMORPG), adalah Game dimana pemain bermain dalam dunia yang skalanya besar (>100 pemain), setiap pemain dapat berinteraksi langsung seperti halnya dunia nyata. Contoh dari genre permainan ini World of Warcraft, The Lord of the Rings Online: Shadows of Angmar, Final Fantasy, Ragnarok, DOTTA.

\section{F. Mobile Cloud Gaming}

Mobile Cloud Gaming didefinisikan sebagai suatu perangkat mobile yang mampu mengakses cloud sebagai eksternal resource untuk pengolahan skenario dan interaksi untuk menjalankan suatu Game. Ada dua tipe mobile cloud Games [11], yaitu:

1) Mobile cloud video gaming

Pemain mengakses server Game dari portal yang tersedia di mobile phone, kemudian client melakukan inisiasi pada server machine dan menjalan Game yang telah di pilih di mobile phone. Saat Game sedang berjalan di server machine atau virtual machine, sisi client lalu melakukan Game streaming dimana Game berjalan bersamaan pada client dan server machine atau virtual machine di cloud.

\section{2) Mobile browser gaming}

Browser Games merupakan jenis dari Games komputer, banyak dari Game tersebut berjalan di situs jejaring sosial dengan pengguna yang cukup banyak. Server mobile browser Games berjalan di cloud. Sementara web browser pada ponsel berfungsi sebagai interface untuk pemain. Komponen penting dalam mobile browser Games meliputi:

- Game server: aplikasi pada sisi server, yang terdiri dari server-side scripting dan userinterface scripting.

- Communication protocol: untuk mengaktifkan prosedur sebuah Game, komunikasi antara server dengan mobile browser.

- Aplikasi runtime: pada ponsel, aplikasi runtime harus ter-install pada web browser sebagai plugin.

\section{Metodologi Penelitian}

Metode penelitian yang digunakan adalah menggunakan metode pengujian langsung dan memantau trafik data pada perangkat jaringan mikrotik. Pengujian dilakukan pada 3 Game yaitu menggunakan Mikrotik RouterBoard untuk mengkontrol menggunakan trafik monitoring saat masing-masing Game berlangsung. Data bandwidth yang diambil Upload dan Download. Data yang diambil antara lain current aktivitas bandwidth, rata-rata pemakaian bandwidth dan maksimal pemakaian bandwidth. Skenario pengujian yang digunakan sebagai berikut :

- Menggunakan durasi waktu pengujian masing-masing Game dimainkan selama 10 menit.

- Menggunakan grafik atau kualitas gambar yang sedang pada masing-masing Game.

\section{A. Pengaturan Grafik Game Free Fire}

Pengaturan grafik Game Free Fire pada gambar 1, sebagai berikut:

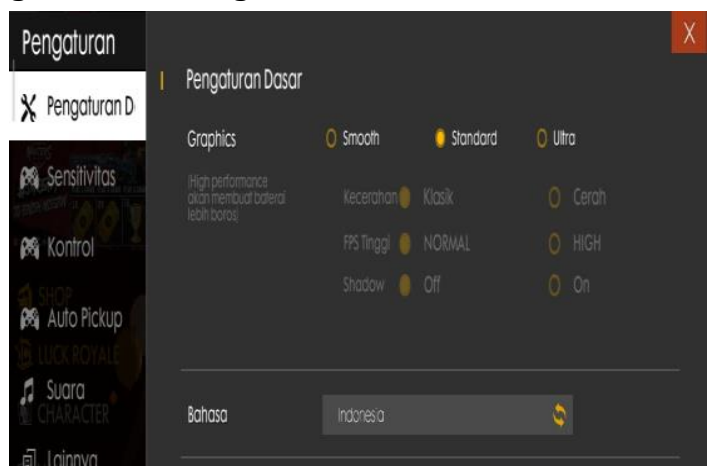

Gambar 1. Pengaturan Grafik Free fire 
Pada gambar 1. menunjukan grafik atau kualitas gambar yang digunakan pada Game Free Fire adalah "Standard" yang dimana ini merupakan opsi yang tidak menggunakan grafik yang rendah (Smooth) dan tidak pula menggunakan grafik yang tinggi (High Quality).

B. Pengaturan Grafik Game Mobile Legends Pengaturan grafik Game Mobile Legends ditunjukkan gambar 2. Gambar 2 menunjukan grafik atau kualitas gambar yang digunakan pada Game Mobile Legends adalah "Medium" yang dimana ini merupakan opsi yang tidak menggunakan grafik yang rendah (Smooth) dan tidak pula menggunakan grafik yang tinggi (High Quality).

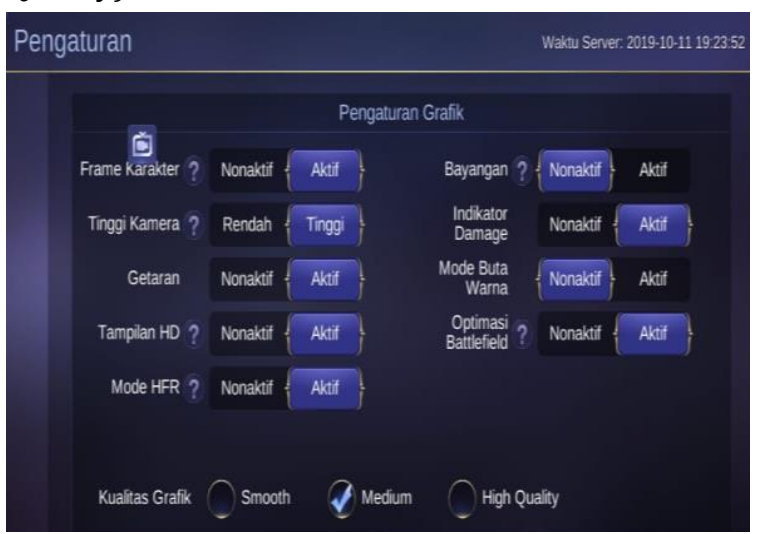

Gambar 2. Pengaturan Grafik Mobile Legends

C. Pengaturan Grafik Game Pubg mobile Pengaturan grafik Game Pubg mobile pada gambar 3, sebagai berikut:

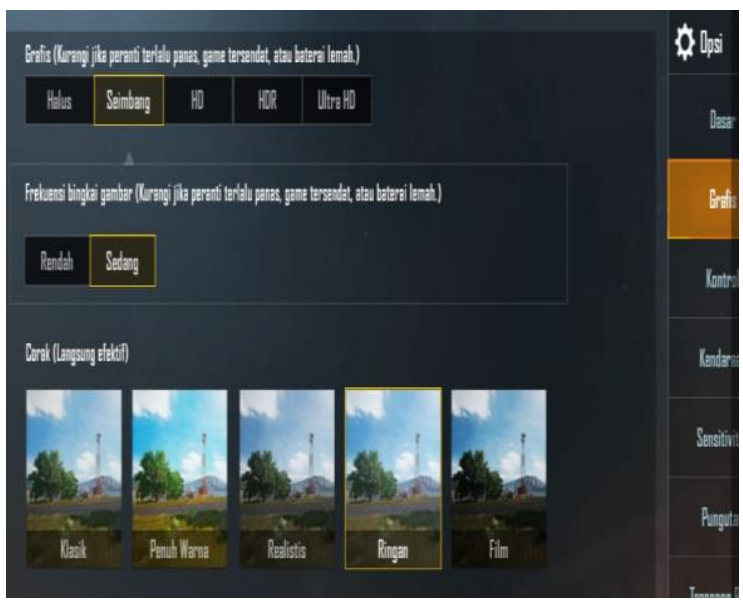

Gambar 3. Pengaturan Grapik Pubg mobile

Pada gambar 3. Menunjukan grafik atau kualitas gambar yang digunakan pada Game Pubg mobile adalah "Seimbang" yang dimana ini merupakan opsi yang tidak menggunakan grafik yang rendah (Halus) dan tidak pula menggunakan grafik yang tinggi (HD).

\section{Hasil dan Pembahasan}

Hasil pengujian yang hasilkan pada 3 Game yang diujikan mendapatkan hasil sebagai berikut:

A. Pengujian Game Free Fire

Pengujian Game Free Fire mendapatkan hasil pada gambar 4 dan tabel 1 sebagai berikut:

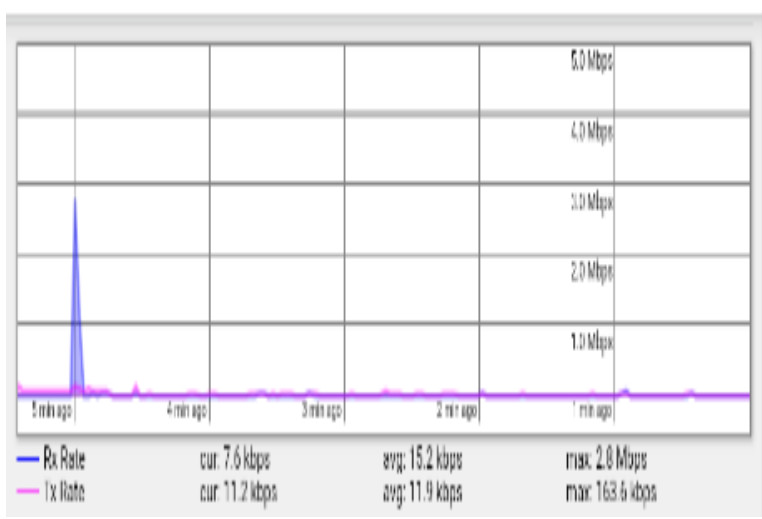

Gambar 4. Pengujian Game Free Fire

Tabel 1. Pengujian Game Free Fire

\begin{tabular}{|c|c|c|c|}
\hline Aktifitas & current & rata-rata & maksimal \\
\hline Upload & $7.6 \mathrm{kbps}$ & $15.2 \mathrm{kbps}$ & $2.8 \mathrm{Mbps}$ \\
\hline Download & $11.2 \mathrm{kbps}$ & $11.9 \mathrm{kbps}$ & $163.6 \mathrm{kbps}$ \\
\hline
\end{tabular}

Pada gambar 4 dan tabel 1. Menunjukan trafik penggunaan bandwidth yang diambil dari monitoring router pada saat Game online free fire dimainankan.

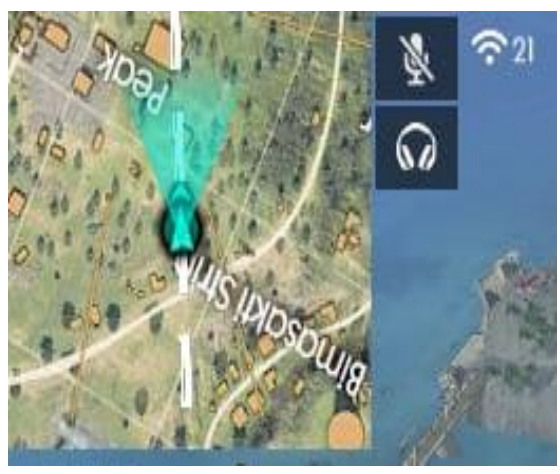

Gambar 5. Sinyal Game Free Fire

Pada gambar 5. Menunjukan sinyal Game Free Fire yang mendapatkan hasil kekuatan sinyal dengan angka 21 artinya sangat bagus 


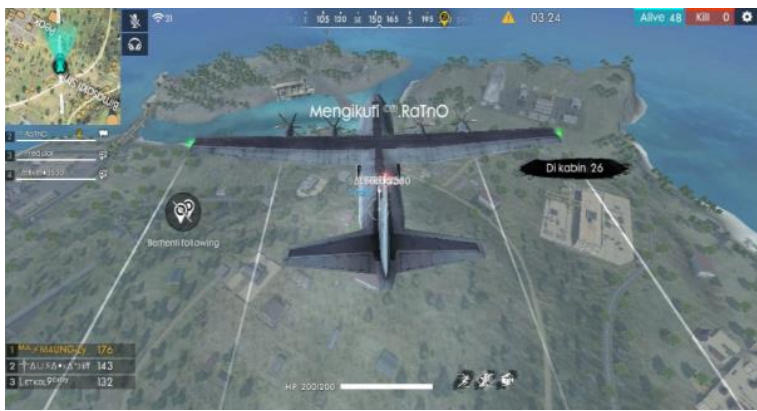

Gambar 6. Tampilan Game Free Fire

Gambar 6 menunjukan tampilan Game Free Fire yang lancar dan stabil tanpa nge-lag.

\section{B. Pengujian Game Mobile Legends}

Pengujian Game Mobile Legends mendapatkan hasil pada gambar 7 dan tabel 2 sebagai berikut:

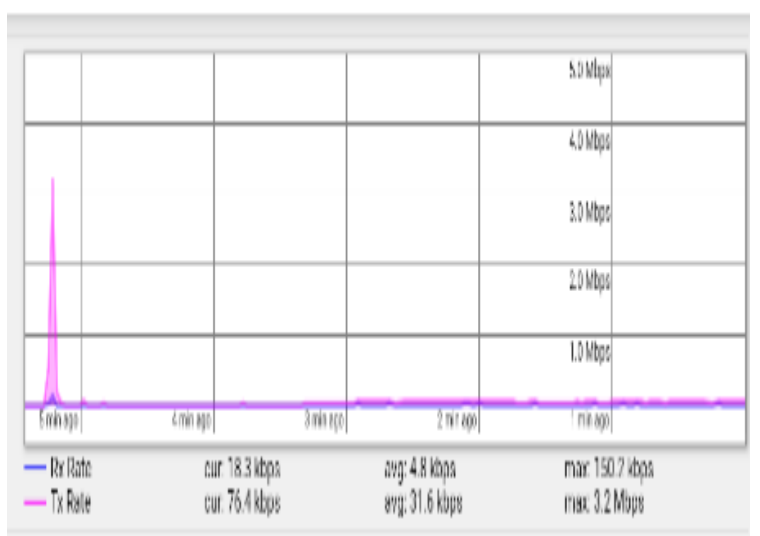

Gambar 7. Pengujian Game Mobile Legends

Tabel 2. Pengujian Game Mobile Legends

\begin{tabular}{|c|c|c|c|}
\hline Aktifitas & current & rata-rata & maksimal \\
\hline Upload & $18.3 \mathrm{kbps}$ & $4.8 \mathrm{kbps}$ & $150.2 \mathrm{kbps}$ \\
\hline Download & $76.4 \mathrm{kbps}$ & $31.6 \mathrm{kbps}$ & $3.2 \mathrm{Mbps}$ \\
\hline
\end{tabular}

Pada gambar 7 dan tabel 2. Menunjukan trafik penggunaan bandwidth yang diambil dari monitoring router pada saat Game online Mobile Legends dimainankan.

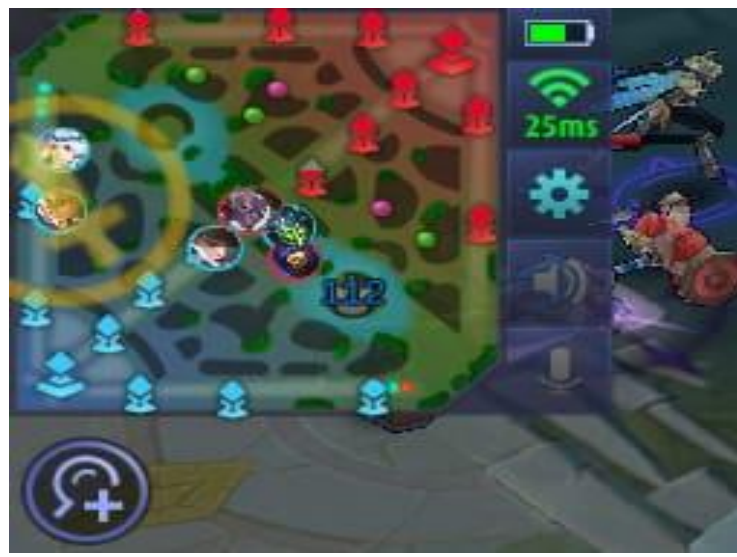

Gambar 8. Sinyal Game Mobile Legends

Pada gambar 8. Menunjukan sinyal Game Mobile Legends yang mendapatkan hasil kekuatan sinyal dengan angka 25 artinya sangat bagus.

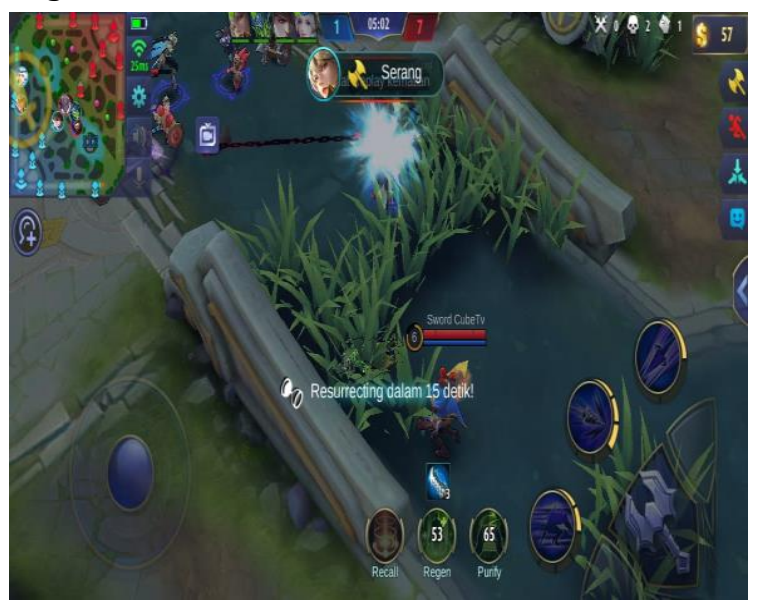

Gambar 9. Tampilan Game Mobile Legends

Pada gambar 9. Menunjukan tampilan Game Mobile Legends yang lancar dan stabil tanpa nge-lag.

C. Pengujian Game Pubg mobile

Pengujian Game Pubg mobile mendapatkan hasil pada gambar 7 dan tabel 2 sebagai berikut: 


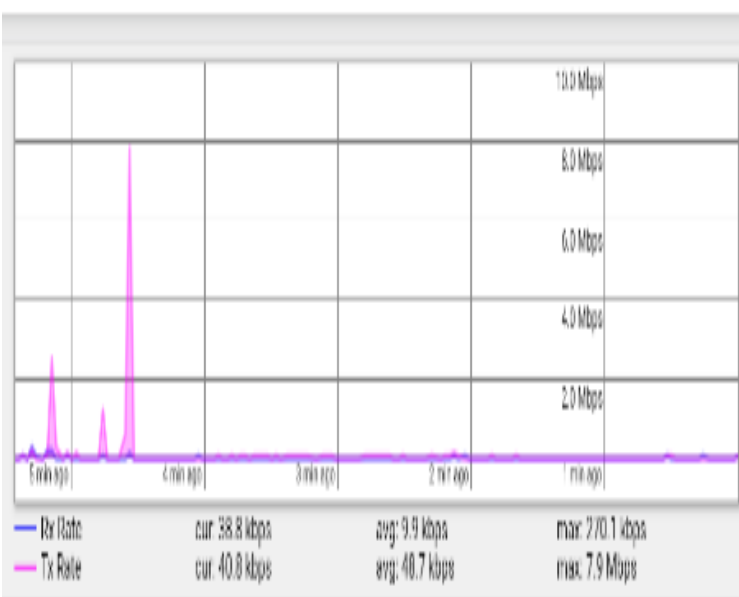

Gambar 10. Pengujian Game Pubg mobile

Tabel 3. Pengujian Game Pubg mobile

\begin{tabular}{|c|c|c|c|}
\hline Aktifitas & current & rata-rata & maksimal \\
\hline Upload & $38.8 \mathrm{kbps}$ & $9.9 \mathrm{kbps}$ & $270.1 \mathrm{kbps}$ \\
\hline Download & $40.8 \mathrm{kbps}$ & $48.7 \mathrm{kbps}$ & $7.9 \mathrm{Mbps}$ \\
\hline
\end{tabular}

Pada gambar 10 dan tabel 3. Menunjukan trafik penggunaan bandwidth yang diambil dari monitoring router pada saat Game online pubg mobile dimainankan.

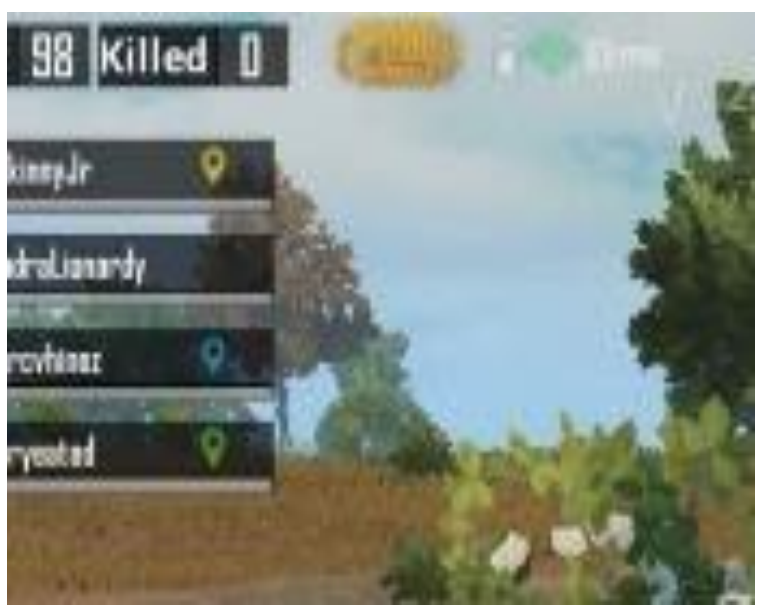

Gambar 11. Sinyal Game Pubg mobile

Pada gambar 11. Menunjukan sinyal Game Pubg mobile yang mendapatkan hasil kekuatan sinyal dengan angka 68 artinya sangat bagus.

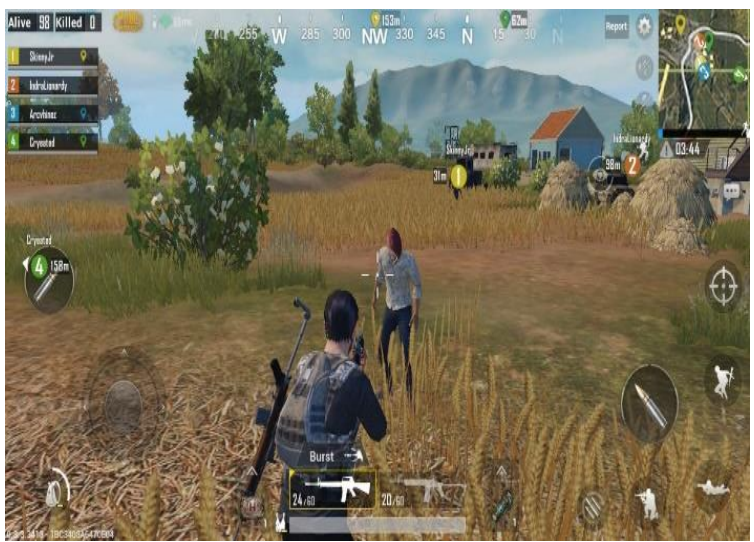

Gambar 12. Tampilan Game Pubg mobile

Pada gambar 12. Menunjukan tampilan Game Pubg mobile yang lancar dan stabil tanpa nge-lag.

D. Perbandingan Kebutuhan Kecepatan Bandwidth Game online

Perbandingan current bandwidth dimasingmasing Game terlihat pada tabel 4 dan gambar 13, sebagai berikut:

Tabel 4. Perbandingan Current Bandwidth

\begin{tabular}{|c|c|c|c|}
\hline No. & Game online & Download & Upload \\
\hline 1. & Free Fire & $11.2 \mathrm{kbps}$ & $7.6 \mathrm{kbps}$ \\
\hline 2. & Mobile Legends & $76.4 \mathrm{kbps}$ & $18.3 \mathrm{kbps}$ \\
\hline 3. & Pubg mobile & $40.8 \mathrm{kbps}$ & $38.8 \mathrm{kbps}$ \\
\hline
\end{tabular}

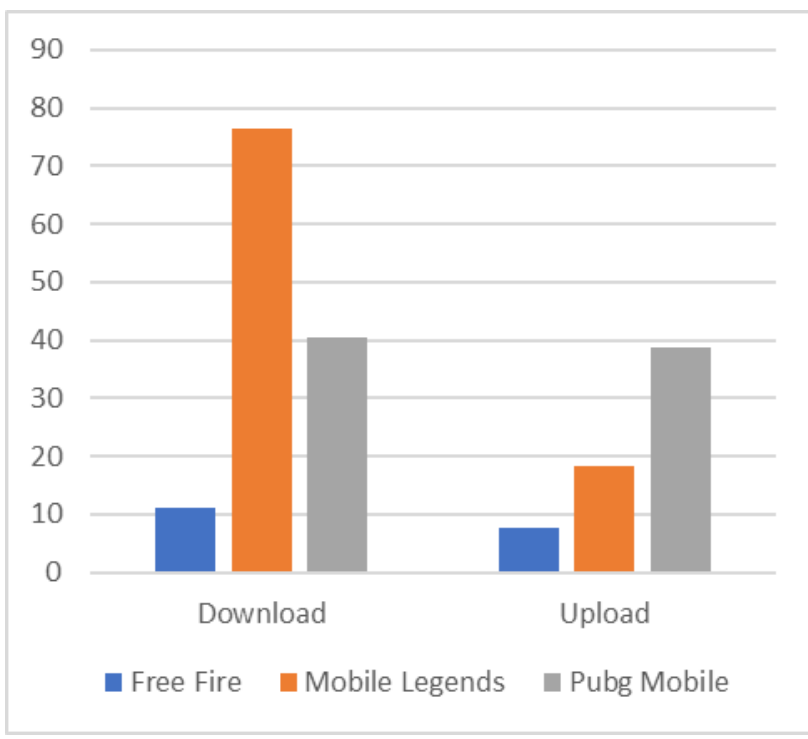

Gambar 13. Grafik Perbandingan Current Bandwidth 
Dilihat dari tabel 4 dan gambar 13 terdapat perbandingan current bandwidth yang menunjukan Mobile Legends mendapatkan Download yang paling tinggi sedangkan pubg mobile mendapatkan Upload yang paling tinggi.

Perbandingan rata-rata bandwidth dimasing-masing Game terlihat pada tabel 5 dan gambar 14, sebagai berikut:

Tabel 5. Perbandingan rata-rata bandwidth

\begin{tabular}{|c|c|c|c|}
\hline No. & Game online & Download & Upload \\
\hline 1. & Free Fire & $11.9 \mathrm{kbps}$ & $15.2 \mathrm{kbps}$ \\
\hline 2. & Mobile Legends & $31.6 \mathrm{kbps}$ & $4.8 \mathrm{kbps}$ \\
\hline 3. & Pubg mobile & $48.7 \mathrm{kbps}$ & $9.9 \mathrm{kbps}$ \\
\hline
\end{tabular}

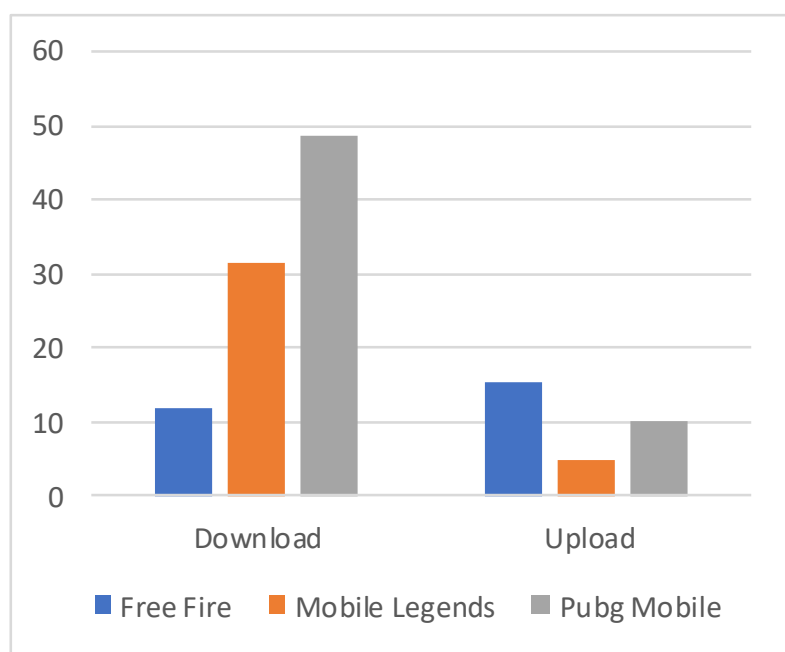

Gambar 14. Grafik Perbandingan Rata-rata Bandwidth

Dilihat dari tabel 5 dan gambar 14 terdapat perbandingan rata-rata bandwidth yang menunjukan pubg mobile mendapatkan Download yang paling tinggi sedangkan free fire mendapatkan Upload yang paling tinggi.

Perbandingan maksimal bandwidth dimasing-masing Game terlihat pada tabel 6 dan gambar 15, sebagai berikut:

Tabel 6. Perbandingan Maksimal Bandwidth

\begin{tabular}{|c|c|c|c|}
\hline No. & Game online & Download & Upload \\
\hline 1. & Free Fire & $163.6 \mathrm{kbps}$ & $2.8 \mathrm{Mbps}$ \\
\hline 2. & Mobile Legends & $3.2 \mathrm{Mbps}$ & $150.2 \mathrm{kbps}$ \\
\hline 3. & Pubg mobile & $7.9 \mathrm{Mbps}$ & $270.1 \mathrm{kbps}$ \\
\hline
\end{tabular}

ISSN. 2620-6900 (Online) 2620-6897 (Cetak)

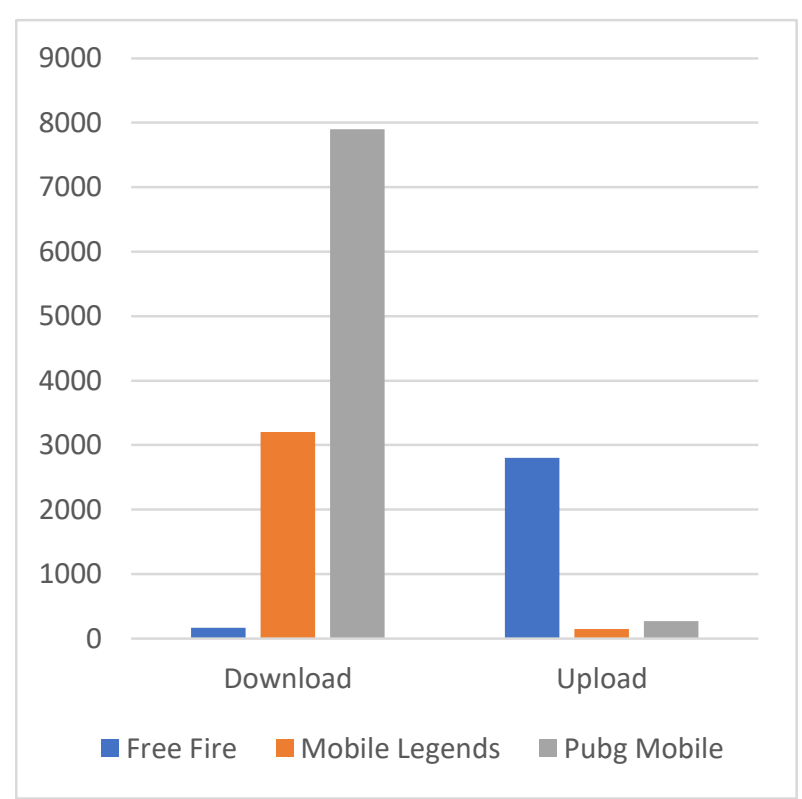

Gambar 15. Grafik Maksimal Bandwidth

Dilihat dari tabel 6 dan gambar 15 terdapat perbandingan maksimal bandwidth yang menunjukan pubg mobile mendapatkan Download yang paling tinggi hal ini disebabkan pada saat login pertama bermain Game membutuhkan atau kenaikan bandwidth Download yang tinggi sedangkan free fire mendapatkan Upload yang paling tinggi disebabkan pada saat login pertama bermain Game membutuhkan atau kenaikan bandwidth Upload yang tinggi.

\section{Kesimpulan dan Saran}

Berdasarkan hasil penelitian yang telah dilakukan, maka dapat disimpulkan sebagai berikut:

1. Pada saat memainkan game Free Fire menggunakan bandwidth rata-rata Download sebesar 11.9 kbps dan Upload sebesar 15.2 kbps.

2. Pada saat memainkan game Mobile Legends menggunakan bandwidth rata-rata Download sebesar 31.6 kbps dan Upload sebesar 4.8 kbps.

3. Pada saat memainkan game Pubg Mobile menggunakan bandwidth rata-rata Download sebesar 48.7 kbps dan Upload sebesar 9.9 kbps.

4. Dilihat dari rata-rata pemakaian bandwidth menunjukan pubg mobile mendapatkan Download yang paling tinggi dengan angka 48.7 kbps dengan sedangkan free fire mendapatkan Upload yang paling tinggi dengan angka $15.2 \mathrm{kbps}$. 
5. Dilihat dari maksimal pemakaian bandwidth menunjukan pubg mobile mendapatkan Download yang paling tinggi angka 7.9 Mbps disebabkan pada saat login pertama main game membutuhkan bandwidth Download yang tinggi sedangkan free fire mendapatkan Upload yang paling tinggi dengan angka 2.8 Mbps disebabkan pada saat login pertama main game membutuhkan bandwidth Upload yang tinggi.

Adapun saran untuk penelitian selanjutnya sebagai berikut:

1. Melakukan perbandingkan dengan game online yang lain seperti Call of Duty, AOV Arena of Valor: Action MOBA, Lineage2 Revolution dan game-game yang lain.

2. Melakukan perbandingan game online menggunakan personal komputer (PC) dengan menginstal game yang akan ingin diujikan.

3. Melakukan pengujian ulang dengan gambar grafik low quality dan high quality pada setiap game online.

4. Dilihat dari hasil rata-rata pemakaian bandwidth dapat disarankan untuk ISP atau RT/RW.Net mengatur bandwidth untuk masing-masing game demi kenyamanan gemer dengan ketentuan yang dihasilkan dari penelitian ini sebagai berikut :

- Untuk game Free Fire dengan Download sebesar 1 Mbps dan Upload sebesar 3 Mbps untuk menghindari lonjakan kenaikan bandwidth pada saat login pertama kali.

- Untuk game Mobile Legends dengan Download sebesar 3,5 Mbps dan Upload sebesar 1 Mbps untuk menghindari lonjakan kenaikan bandwidth pada saat login pertama kali.

- Untuk game Pubg Mobile dengan Download sebesar 8 Mbps dan Upload sebesar 1 Mbps untuk menghindari lonjakan kenaikan bandwidth pada saat login pertama kali.

\section{Daftar Pustaka:}

[1] E. S. Mulyanta, Pengenalan Protokol Jaringan Wireless Komputer. Yogyakarta: Andi, 2005.

[2] A. F. D. Ananta, F. Suryawan, and Dedi Ari Prasetya, "Routing Warnet Dan Game online Di Mitha.Net Menggunakan Dua Line Speedy Dengan Mikrotik," in Publikasi Ilmiah Universitas Muhammadyah Surakarta, Surakarta: Teknik Informatika, Fakultas Komunikasi dan Informatika, Universitas Muhammadyah Surakarta, 2013.

[3] E. Setiawan, R. Munadi, and Sussi, "Implementasi Dan Analisis Mobile Cloud Gaming Online Menggunakan Open-source Cloud Gaming Server Gaminganywhere Pada Perangkat Android," in e-Proceeding of Engineering, 2017, vol. 4, no. 3, pp. 3580-3587.

[4] N. U. Mutia, I. D. Irawati, and R. Mayasari, "Analisis Performasi Jaringan Untuk Layanan Interaktif, Studi Kasus GameOnline Pada Jaringan IP," in Teknik Telekomunikasi, Fakultas Teknik Elektro, Universitas Telkom, Bandung, 2012.

[5] V. B. Togohodoh, "Manajemen Bandwidth Dengan Metode Peer Connection Queue (PCQ) Menggunakan Queue Tree," in Skripsi Program Studi Teknik Informatika Faqultas Sains Dan Teknologi Universitas Sanata Dharma Yogyakarta, Yogyakarta: Faqultas Sains Dan Teknologi Universitas Sanata Dharma Yogyakarta, 2018, p. 81.

[6] P. Norton and D. Kearns, Complete Guide to Networking. USA: Sams Publishing, 1999.

[7] E. S. Dewo, "Bandwidth dan Throughput," IlmuKomputer.Com, pp. 1-3, 2003.

[8] Athailah, Mikrotik untuk Pemula. Jakarta: Mediakita, 2013.

[9] Bakti, W., Imtihan, K., \& Pardiansyah, A. S. (2018). Proxy Server dan Management Bandwidth Jaringan Komputer Menggunakan Mikrotik RB952Ui5ac2nD (Studi Kasus MA Ishlahul Ikhwan Nahdlatul Wathan Mispalah Praya). Jurnal Informatika dan Rekayasa Elektronik, 1(1), 44-49.

[10] Fadli, S., \& Imtihan, K. (2018). ANALISIS DAN PERANCANGAN SISTEM ADMINISTRASI DAN TRANSAKSI BERBASIS CLIENT SERVER. Jurnal Informatika dan Rekayasa Elektronik, 1(2), 7-14.

[11] Supriadi, D., Fahmi, H., \& Imtihan, K. (2018). ANALISA DAN PERANCANGAN INFRASTRUKTUR JARINGAN WIRELESS 
LOCAL AREA NETWORK (WLAN) PADA DINAS PERINDUSTRIAN DAN PERDAGANGAN KABUPATEN LOMBOK TENGAH. Jurnal Informatika dan Rekayasa Elektronik, 1(2), 1-6.

[12] R. Julianre, "Keberfungsian Sosial Orang Dewasa Pengguna Game online (Studi Kasus Di Kelurahan Panorama)," Universitas Negeri Bengkulu, 2014.
[13] B. L. Grace, "Game Type and Game Genre," www.researchgate.net, 2005.

[14] W. Cai, V. C. M. Leung, and M. Chen, "Next generation Mobile Cloud Gaming," IEEE Seventh International Symposium on Service-Oriented System Engineering, 2013.," in SOSE '13 Proceedings of the 2013 IEEE Seventh International Symposium on Service-Oriented System Engineering, 2013, pp. 551-560. 